\title{
Water replenishment for ecological flow with E-WAS framework: a case study of the Longgang River Basin, Shenzhen, China
}

\author{
Ziqi Yan, Zuhao Zhou, Xuefeng Sang, Hao Wang, and Yangwen Jia \\ State Key Laboratory of Simulation and Regulation of Water Cycle in River Basin, \\ China Institute of Water Resources and Hydropower Research, Beijing 100038, China \\ Correspondence: Ziqi Yan (yanzq@iwhr.com) \\ Published: 16 September 2020
}

\begin{abstract}
With rapid urbanization, there will be more conflict between human systems and the riverine ecological system, and therefore, ecological operations, practices and research must involve the ecological water replenishment of entire river basins with new modeling tools. In this study, we establish an ecological flow-oriented water resource allocation and simulation framework (E-WAS). Virtual reservoirs and ecological units are added to the water resources network. With new water balance equations for virtual reservoirs and ecological units, the E-WAS can simulate the ecological replenishment process in a river basin and can provide a recommended water replenishment scheme that considers optimization principles. The E-WAS was applied in the Longgang River Basin, Shenzhen, China. 17 ecological units and 45 water supply nodes are considered in the model. A water replenishment scheme that used water from 31 reservoirs and reclaimed water from 7 water sewage plants was selected. This scheme significantly increased the satisfactory degree of ecological water demand and efficiently supported the formulation of a control scheme for the water environment of a basin. The E-WAS framework is similar to model plug-ins but helps to avoid the large workload that is required for model redevelopment and can expand the functions of models quickly.
\end{abstract}

\section{Introduction}

Replenishing ecological water through reservoir operation has become a major metric for the restoration of river ecosystems worldwide. In general, an ecological replenishment scheme is implemented to restore the natural ecosystem of a river basin consists by adjusting reservoir release and restoring the natural rhythm of the river flow as much as possible, at the same time ensuring flood control and no significant decrease in benefit (e.g., power generation and irrigation) (Higgins and Brock, 1999; Symphorian et al., 2003; Gippel et al., 2002; Dong, 2007). Existing research regarding ecological reservoir operation mainly focuses on the theories of and calculation methods for the ecological water requirements of river channels, optimization of hydraulic and hydropower engineering systems, water and sediment control in reservoirs, ecological flood control, water quality protection, habitat improvement for organisms in reservoirs and downstream river channels, the evaluation of ecological operation schemes and legislation for ecological operation (Junk, 1982; Petts, 1996; Hughes and Hannart, 2003). Many researchers have studied methods of improving river ecology (Wang et al., 2014; Galat et al., 1998; Day et al., 2012), and noted that the water replenishment strategy is effective for river protection. Although reservoir construction affects the original hydrological form of a river, reservoirs are also used for flood regulation, which can mitigate the imbalance of water in rivers. The provision of supplemental water to rivers by reservoirs during emergencies has been discussed by Yang et al. (2008). Several scenarios have been initiated in China to release reservoir water into adjacent rivers. For example, water was released from the Nenjiang reservoir into the Zhalong wetlands (Zhou et al., 2007), from the Xiaolangdi hydropower reservoir into the Yellow River (Cui et al., 2009), and from upstream reservoirs into the Tarim River (Huang and Pang, 2010). 
In this study, based on a basin-scale water resource allocation and simulation model (WAS), we establish an ecological flow-oriented water resource allocation and simulation framework (E-WAS) to expand the functions of the WAS model. E-WAS can account for ecological flows, in which multiple water resources are allocated to meet the water requirements for various purposes. This study will help decision-makers formulate ecological water replenishment schemes for river basins at the planning level. The remainder of this paper is structured as follows. Section 2 describes the WAS model and derives the E-WAS framework, Sect. 3 describes the application of the E-WAS framework in the Longgang River Basin, and Sect. 4 discusses the results. Section 5 concludes the paper.

\section{The E-WAS framework}

The E-WAS (ecological flow-oriented WAS model) framework (Yan et al., 2018) is based on the traditional water resource allocation model (WAS), which can dually simulate natural-artificial water cycles that are influenced by both nature and humans (Wang et al., 2014; Zhai et al., 2017; Sang et al., 2010). In order to control multiple types of water sources and dynamically allocate water resources to replenish the ecological water of the river in the model, a virtual reservoir is used in the E-WAS system network and is used in conjunction with the ecological units. The storage capacity of the virtual reservoir is set to "zero" so it does not regulate and store water. The function of the virtual reservoir is to receive the water that is released from the reservoir upstream of the ecological units, the inter-zonally generated water and the water that is exported from external sources. All the water that is imported into the virtual reservoir will be directly supplied to the ecological units to meet their ecological water requirements. Because the water consumption for the ecological unit is also set to "zero", the ecological water that is supplied to the present unit can all be released to the downstream river channel. In addition, because its storage capacity is "zero", the surplus water in the virtual reservoir will also be directly released to the downstream river channel.

Here, an example is presented to illustrate the new water resource allocation network in E-WAS (Fig. 1). The water system consists of a reservoir A, a social water consumption unit $\mathrm{B}$ and a control section of ecological flow $\mathrm{C}$ at the location where a tributary flows into the main stream (Fig. 1a). First, an ecological unit $\mathrm{C}^{\prime}$ is set by generalizing the ecological flow section C (Fig. 1b). Then, a virtual reservoir D is set upstream of the ecological unit $C^{\prime}$ (Fig. 1c) and is used in conjunction with ecological unit $\mathrm{C}^{\prime}$. The storage capacity of virtual reservoir D is set to "zero". The function of virtual reservoir D is to receive the water that is released from the upstream reservoir $\mathrm{A}$ and the inter-zonally generated water from the area between $A$ and $C^{\prime}$, where it does not regulate and store water. All of the water that is imported into virtual
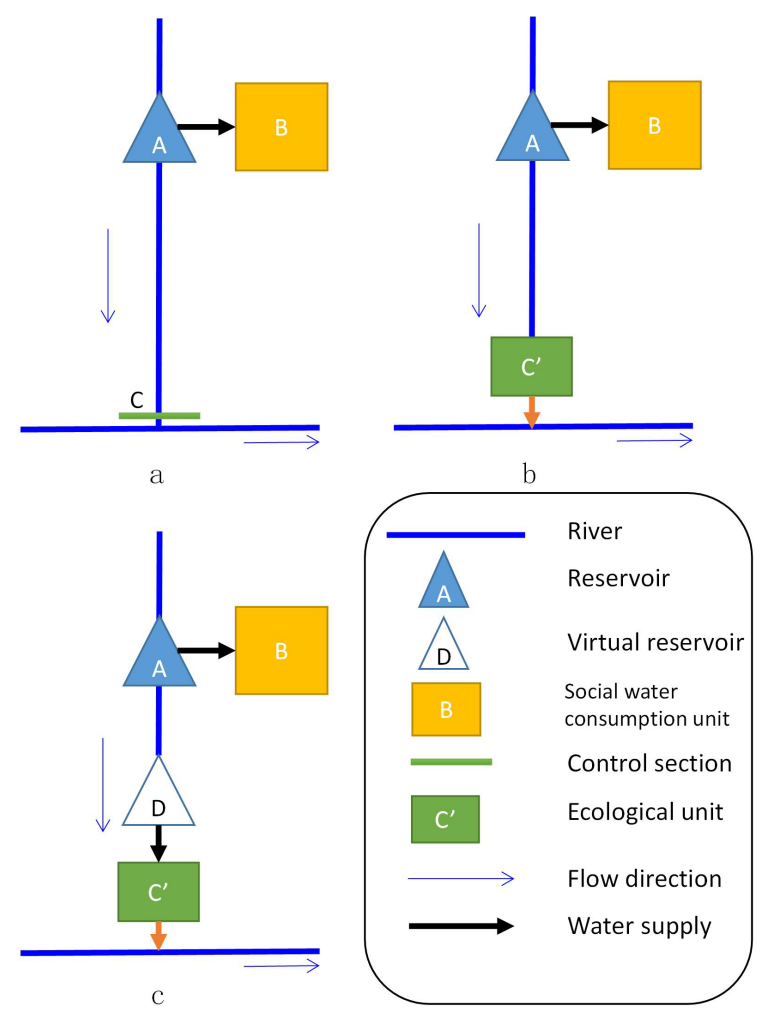

Figure 1. Water resource allocation network in E-WAS (Yan et al., 2018).

reservoir $\mathrm{D}$ is directly supplied to ecological unit $\mathrm{C}^{\prime}$ to meet its ecological water requirements. Because there is no water consumption in ecological unit $\mathrm{C}^{\prime}$, all of the ecological water that is supplied to ecological unit $\mathrm{C}^{\prime}$ is released to the downstream river channel. Because its storage capacity is "zero", the surplus water in virtual reservoir D will also be directly released to the downstream river channel.

The computation within the E-WAS framework should follow the following rules: The water (flood water during the flood season, water released from the reservoir, etc.) that is released from the reservoir upstream of the virtual reservoir and the inter-zonal confluent water all flows into the virtual reservoir. The inflow water is first supplied to the ecological unit, and the surplus water is released. If the inflow water from the upstream reservoir and the inter-zonal confluent water cannot meet the water requirements of the ecological unit, a water transfer command will be sent to the upstream reservoir. Upon receiving this command, the upstream reservoir will transfer water to the virtual reservoir to replenish the downstream ecological unit with water.

The E-WAS framework is capable of coupling reservoir operations for ecological flow and water resource allocation optimization. It can provide an optimal water allocation scheme with ecological flow requirements by improving the computational procedure in WAS and supplementing it with a virtual reservoir and an ecological unit, without imparting 
significant changes in the internal core algorithm of the WAS model. The equations under the E-WAS framework undergo the following changes.

1. Water balance equation for a virtual reservoir:

$\mathrm{QR}=0$

$Q_{\text {rin }}+Q_{\text {rin } 0}+Q_{\text {rin } 1}=Q_{\text {rko }}+Q_{\text {rfo }}$

where QR is the amount of water stored in the virtual reservoir $\left(10000 \mathrm{~m}^{3}\right) ; Q_{\text {rin }}$ is the inter-zonal water inflow; $Q_{\text {rino }}$ is the amount of water released from the upstream physical reservoir $\left(10000 \mathrm{~m}^{3}\right) ; Q_{\text {rin1 }}$ is the amount of water imported from the upstream physical reservoir $\left(10000 \mathrm{~m}^{3}\right)$; $Q_{\text {rko }}$ is the amount of water supplied by the virtual reservoir $\left(10000 \mathrm{~m}^{3}\right)$; and $Q_{\text {rfo }}$ is the amount of water released from the virtual reservoir $\left(10000 \mathrm{~m}^{3}\right) . Q_{\text {rko }}$ refers to the amount of water supplied to meet ecological water requirements. When the interzonal water inflow and the water that is released from the upstream reservoir and received by the virtual reservoir cannot meet the corresponding water requirements of the ecological unit, the virtual reservoir will send a water transfer command to the upstream physical reservoir. If there is surplus water in the upstream physical reservoir after it completes the water supply task, it will transfer water to the virtual reservoir, and the amount of water transferred is $Q_{\text {rin1 }}$. The amount of water imported from the physical reservoir can then be treated as the water transferred for ecological replenishment, i.e., the water is specifically released by the physical reservoir to meet the ecological flow requirements of the river channel. While the water released from the upstream reservoir, or $Q_{\text {rin } 0}$, also forms an ecological flow, it is not actively released by the upstream reservoir to meet the ecological target.

2. Water balance equation for an ecological unit:

$\mathrm{QU}=\mathrm{QU}_{\text {resu }}+\mathrm{QU}_{\mathrm{wru}}+\mathrm{QU}_{\text {oresu }}$

where QU is the water used by the ecological environment within the time period $\left(10000 \mathrm{~m}^{3}\right) ; \mathrm{QU}_{\text {resu }}$ is the water supplied to the virtual reservoir $\left(10000 \mathrm{~m}^{3}\right)$; $\mathrm{QU}_{\text {wru }}$ is the water supplied by reclaimed water sources (if there is a water purification plant in this river segment, the released tail water can be used as the water supplied by reclaimed water sources, and the quality of reclaimed water must meet the high standard for ecological flow) $\left(10000 \mathrm{~m}^{3}\right)$; and $\mathrm{QU}_{\text {oresu }}$ is the water imported into the reservoir from external sources $\left(10000 \mathrm{~m}^{3}\right)$.

3. Objective functions and their solutions:

Regional water supply security and equity are the core objectives of water resource allocation. The WAS model uses optimum equity and a minimum water supply deficiency ratio as the objective functions for water resource allocation optimization (Yang et al., 2016).

a. Equity objective:

$$
\begin{aligned}
& \operatorname{Min} F(x)=\sum_{y=1}^{\mathrm{myr}} \sum_{n=1}^{12} \sum_{h=1}^{\mathrm{mh}} q_{h} \cdot \operatorname{GP}\left(X_{h}\right) \\
& \operatorname{GP}\left(X_{h}\right)=\sqrt{\frac{1}{\mathrm{mu}-1} \sum_{u=1}^{\mathrm{mu}}\left(x_{h}^{u}-\overline{x_{h}}\right)^{2}}
\end{aligned}
$$

where $F(x)$ is the equity objective; $\operatorname{GP}\left(x_{h}\right)$ is the equity function; $q_{h}$ is the sectorial user penalty function; $x_{h}^{u}$ is the water deficiency ratio for sectorial user $h$ in unit $u$; $\overline{x_{h}}$ is the average water deficiency ratio for sectorial user $h$ in unit $u$; myr is the number of years within the calculation period; $n$ is the monthly id within the year; mh is the number of sectorial water-use types in the region; and mu is the number of units in the region.

b. Minimum water deficiency ratio objective:

$$
\begin{aligned}
& \operatorname{Min} Y(x)=\sum_{y=1}^{\mathrm{myr}} \sum_{n=1}^{12} \sum_{h=1}^{\mathrm{mh}} q_{h} \cdot \mathrm{SW}\left(X_{h}\right) \\
& \mathrm{SW}\left(X_{h}\right)=\frac{1}{\mathrm{mu}} \sum_{u=1}^{\mathrm{mu}}\left|\left(x_{h}^{u}-\mathrm{Sob}_{h}^{n}\right)\right|
\end{aligned}
$$

where $Y(x)$ is the water supply stress objective; $\mathrm{SW}\left(x_{h}\right)$ is the water supply stress function; $q_{h}$ is the sectorial user penalty function; $x_{h}^{u}$ is the water deficiency ratio for sectorial user $h$ in unit $u$; $\operatorname{Sob}_{h}^{n}$ is the ideal value of the water supply stress objective of each month for sectorial user $h$ in the region; myr is the number of years within the calculation period; $n$ is the identification of the month within the year; $\mathrm{mh}$ is the number of sectorial water-use types in the region; and mu is the number of units in the region.

\section{Application}

\subsection{Study area and data}

The Longgang River Basin is located in northeastern Shenzhen (Fig. 2). The Longgang River Basin is in the South Asian tropical monsoon climate zone. The annual mean temperature is $22.3^{\circ} \mathrm{C}$. The average annual precipitation is $2073.5 \mathrm{~mm}$, precipitation during the flooding season (AprilSeptember) accounts for proximately $85 \%$ of the annual precipitation, and precipitation during the dry season (OctoberMarch) only proximately $15 \%$. With rapid economic development, water shortages in the Longgang River basin have 
become increasingly serious. Historically abundant local water resources are becoming increasingly precious. Thus, no ecological flow is set during the operation scheme of the local reservoirs in this river basin, and all water resources are stored in the reservoirs for urban uses, even if it is unnecessary in wet seasons. Thus, most river channels in the basin are dry. In contrast, some usable reclaimed water resources remain in the Longgang River Basin. Although the water from sewage plants is sufficiently clean, further research is required to determine how it can be used for ecological flow. Thus, it is necessary to perform a systematic analysis of water resource allocation to formulate a scheme to ensure ecological flows in river channels with multiple types of water sources in the Longgang River Basin.

According to the Statistical Handbook of Water Affairs of Shenzhen and the Shenzhen Municipality's Plan for Optimization and Adjustment of Reservoirs, there are 18 reservoirs in the Longgang River Basin. Long-term hydrological and meteorological data (from 1985 to 2015) were obtained from in the Statistical Yearbooks of Hydrological Data of Shenzhen. Information for the water system and river network was extracted based on a $30 \times 30 \mathrm{~m}$ DEM.

\subsection{Control sections and ecological flow requirements}

To achieve refined water replenishment in the Longgang River Basin, control sections for ecological flow requirements are determined based on the following principles. (1) Particular consideration is given to the river sections where there are sudden changes in parameters (e.g., the flow in the river segment). (2) The catchment areas that are controlled by each section can be treated as a relatively independent sub-ecological areas that are capable of performing specific ecological functions. According to these principles, 17 sections of the Longgang River are selected as control sections for ecological water requirements, of which 3 are sections of the main stream (in the upper, middle and lower reaches) and 14 are sections of tributaries (Fig. 3).

\section{Ecological flow requirements}

There are several methods for calculating the ecological flow in a river, such as the 7Q10 method (Singh and Stall, 1974), the wetted perimeter method (Gippel and Stewardson, 1998), the R2CROSS method (Gregoiy, 1996), IFIM (Gore and Nestler, 1988), and the Tennant method (Tennant, 1976). Based on previous studies that considered the ecological water requirements of Shenzhen, the Tennant method is used to determine the minimum ecological flow requirements. Based on this method, $30 \%$ (non-flood season) or $40 \%$ (flood season) of the average annual runoff is used as the suitable ecological water requirements of each river channel (Mao et al., 2009; Armbruster, 1976; Binns and Eiserman, 1979; King and Louw, 1998). Based on the specific characteristics of the Longgang River Basin, April through October is set as the flood season and November through March of the following year is set as the non-flood season (Table 1).

\subsection{Water resource allocation network based on the E-WAS}

To achieve ecological water replenishment in the Longgang River Basin, it is necessary to first establish a water resource allocation network under E-WAS, in which social and economic water consumption must be taken into consideration. Particular consideration should be given to ecological flow requirements at the control sections of the rivers. Thus, the Longgang River Basin is divided into 5 computational units, of which one is a social and economic water consumption unit, and 17 are ecological units for ecological water requirements (Table 2).

By analyzing the reservoirs and sewage plants in the Longgang River Basin, 45 water supply nodes are established, of which 31 are reservoir nodes, 17 are virtual reservoir nodes and 7 are reclaimed water supply nodes. All the reclaimed water in this network is derived from treated wastewater used for a certain purpose after strict treatment. Due to the high discharge standards, the reclaimed water can be used for water replenishment in the river, and is treated as clean water in the model. In addition, an external water source must be considered, namely, the Eastern water diversion system. Figure 4 shows the water resource network based on the E-WAS framework. Each tributary is treated as an ecological unit with ecological water requirements. In addition, the upper, middle and lower reaches of the main stream are also treated as an ecological unit with ecological water requirements.

\subsection{Model calibration and validation}

Model calibration and validation is a key process in verifying model simulation accuracy and calibrating model parameters. The model used in this study involves the water cycle module and the water resource allocation module. First, the water cycle module is validated mainly based on runoff at the key sections. Then, the water resource allocation scheme is examined based on the published amount of water supply for social and economic purposes.

\subsubsection{Runoff simulation validation}

The model simulation results were evaluated based on the Nash-Sutcliffe efficiency coefficient (NSE) and the regression coefficient $\left(R^{2}\right)$ between the simulated and observed runoff data from 1985 to 2015 from the stations in the lower reaches of the Longgang River. Model simulations were performed for the period from 1961 to 2015. The first 30 years were used for model calibration, and the last 25 years were used for model validation. The runoff simulation results show that the model has an NSE of 0.86 and an $R^{2}$ of 0.87 for the calibration period and an NSE of 0.84 and an $R^{2}$ of 


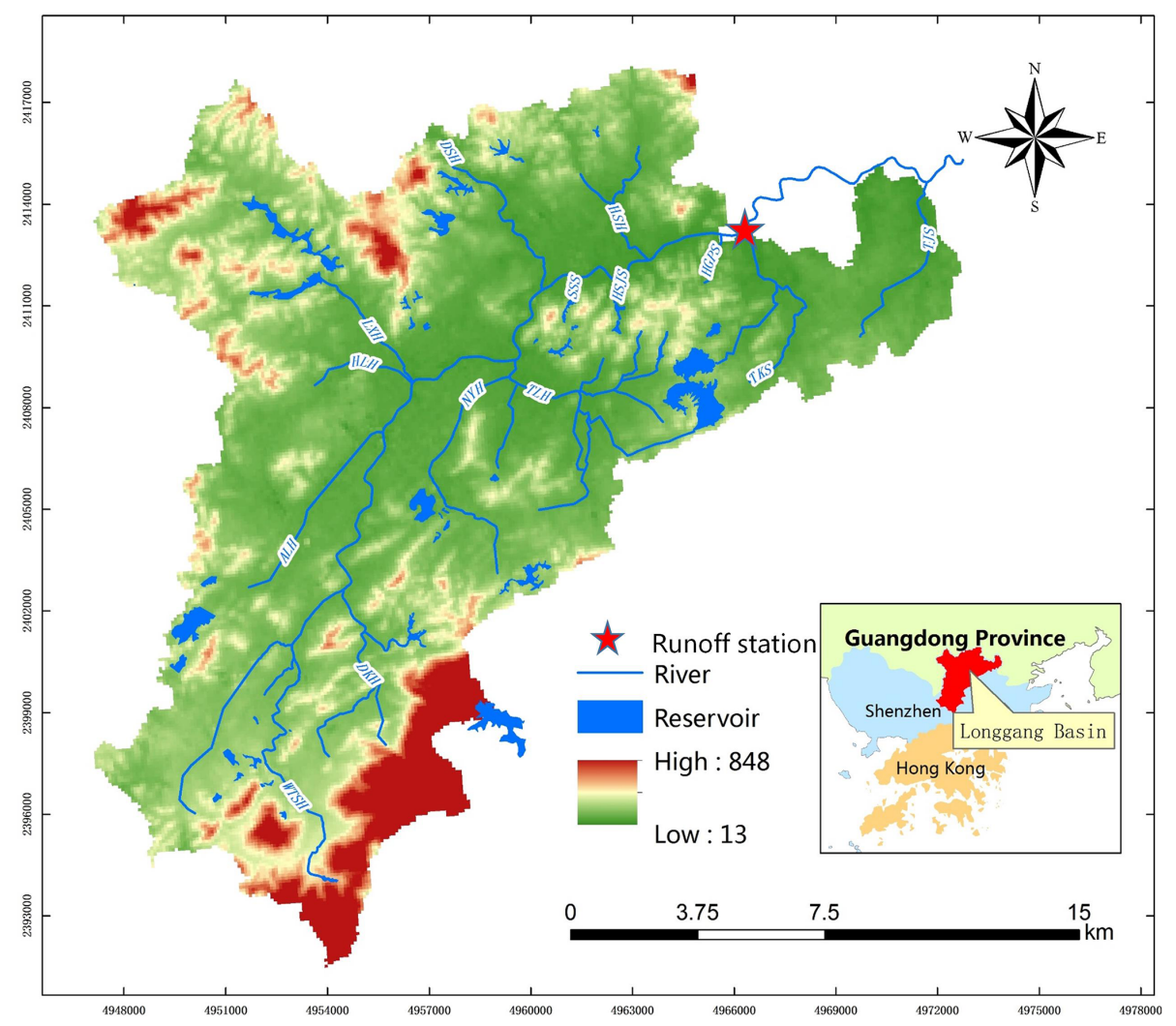

Figure 2. The Longgang River Basin.

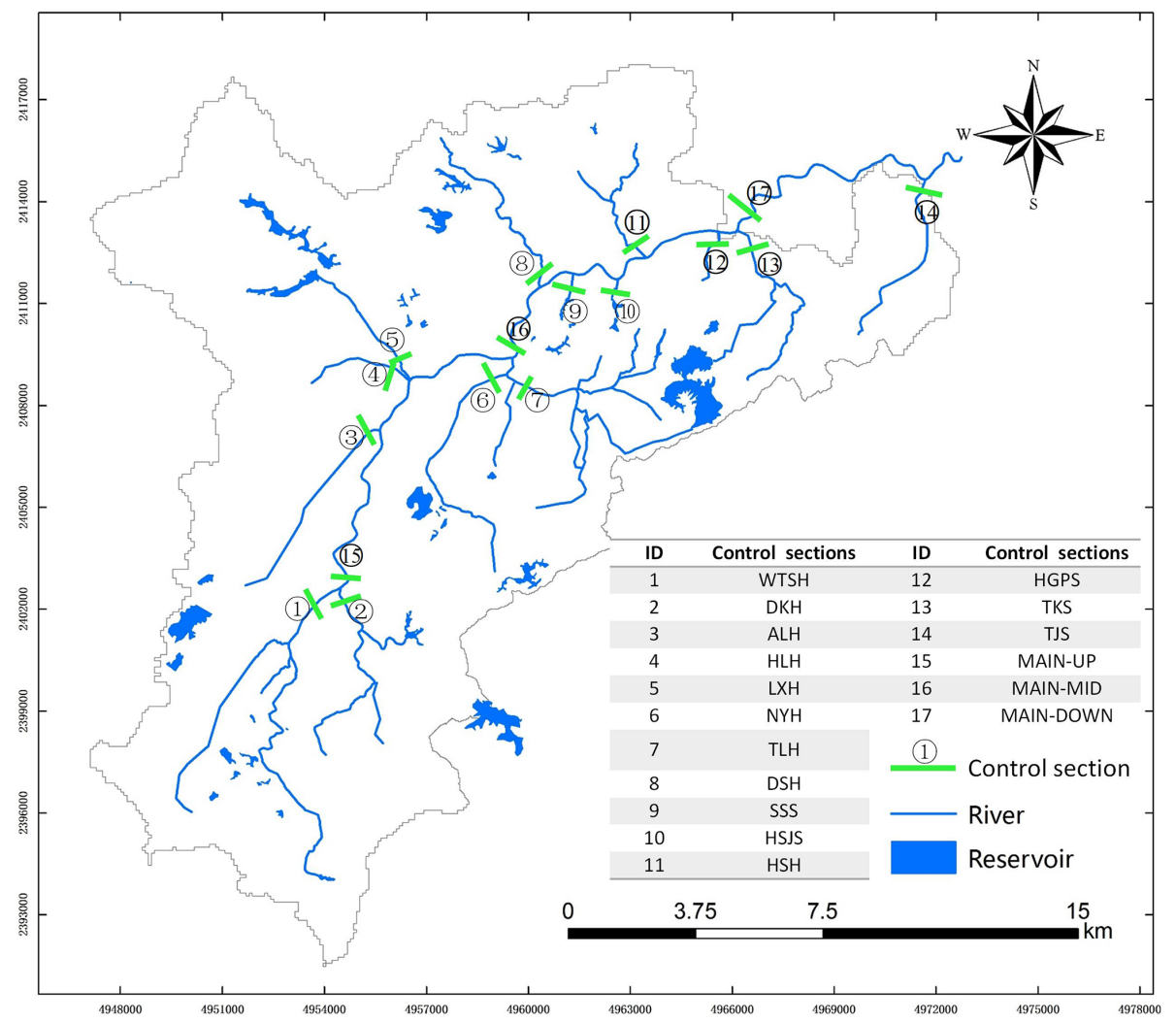

Figure 3. Control sections for ecological flow in the Longgang River Basin. 
Table 1. Suitable ecological water requirements $\left(10000 \mathrm{~m}^{3}\right)$.

\begin{tabular}{|c|c|c|c|c|c|c|c|c|c|c|c|c|c|}
\hline ID & Control sections & Jan & Feb & Mar & Apr & May & Jun & Jul & Aug & Sep & Oct & Nov & Dec \\
\hline 1 & WTSH & 13.8 & 22.9 & 37.2 & 105.8 & 170.9 & 232.1 & 195.3 & 206.3 & 144.2 & 47.2 & 16.6 & 15.0 \\
\hline 2 & DKH & 11.0 & 18.3 & 29.6 & 84.4 & 136.3 & 185.1 & 155.8 & 164.5 & 115.0 & 37.6 & 13.3 & 11.9 \\
\hline 3 & ALH & 9.0 & 14.9 & 24.2 & 68.9 & 111.3 & 151.1 & 127.2 & 134.3 & 93.9 & 30.7 & 10.8 & 9.7 \\
\hline 4 & HLH & 6.4 & 10.6 & 17.2 & 49.1 & 79.3 & 107.8 & 90.7 & 95.8 & 66.9 & 21.9 & 7.7 & 6.9 \\
\hline 5 & LXH & 19.6 & 32.5 & 52.7 & 150.0 & 242.3 & 329.1 & 276.9 & 292.4 & 204.4 & 66.9 & 23.6 & 21.2 \\
\hline 6 & NYH & 21.5 & 35.6 & 57.8 & 164.5 & 265.7 & 360.9 & 303.6 & 320.7 & 224.1 & 73.4 & 25.8 & 23.3 \\
\hline 7 & TLH & 13.0 & 21.6 & 35.1 & 99.9 & 161.3 & 219.1 & 184.4 & 194.7 & 136.1 & 44.5 & 15.7 & 14.1 \\
\hline 8 & DSH & 34.9 & 57.8 & 93.8 & 267.1 & 431.3 & 585.8 & 492.9 & 520.6 & 363.8 & 119.1 & 42.0 & 37.8 \\
\hline 9 & SSS & 0.9 & 1.4 & 2.3 & 6.6 & 10.6 & 14.5 & 12.2 & 12.9 & 9.0 & 2.9 & 1.0 & 0.9 \\
\hline 10 & HSJS & 0.9 & 1.4 & 2.3 & 6.6 & 10.6 & 14.5 & 12.2 & 12.9 & 9.0 & 2.9 & 1.0 & 0.9 \\
\hline 11 & $\mathrm{HSH}$ & 18.1 & 30.0 & 48.6 & 138.5 & 223.6 & 303.7 & 255.6 & 269.9 & 188.7 & 61.7 & 21.8 & 19.6 \\
\hline 12 & HGPS & 0.9 & 1.4 & 2.3 & 6.6 & 10.6 & 14.5 & 12.2 & 12.9 & 9.0 & 2.9 & 1.0 & 0.9 \\
\hline 13 & TKS & 9.0 & 14.9 & 24.2 & 68.9 & 111.3 & 151.1 & 127.2 & 134.3 & 93.9 & 30.7 & 10.8 & 9.7 \\
\hline 14 & TJS & 5.1 & 8.5 & 13.8 & 39.2 & 63.4 & 86.1 & 72.4 & 76.5 & 53.5 & 17.5 & 6.2 & 5.5 \\
\hline 15 & MAIN-UP & 24.8 & 41.2 & 66.8 & 190.3 & 307.2 & 417.3 & 351.1 & 370.8 & 259.2 & 84.8 & 29.9 & 26.9 \\
\hline 16 & MAIN-MID & 94.3 & 156.5 & 253.8 & 722.8 & 1167.1 & 1585.2 & 1333.8 & 1408.7 & 984.6 & 322.2 & 113.5 & 102.2 \\
\hline 17 & MAIN-DOWN & 145.6 & 241.6 & 391.7 & 1115.7 & 1801.6 & 2447.0 & 2058.8 & 2174.5 & 1519.9 & 497.4 & 175.2 & 157.7 \\
\hline
\end{tabular}

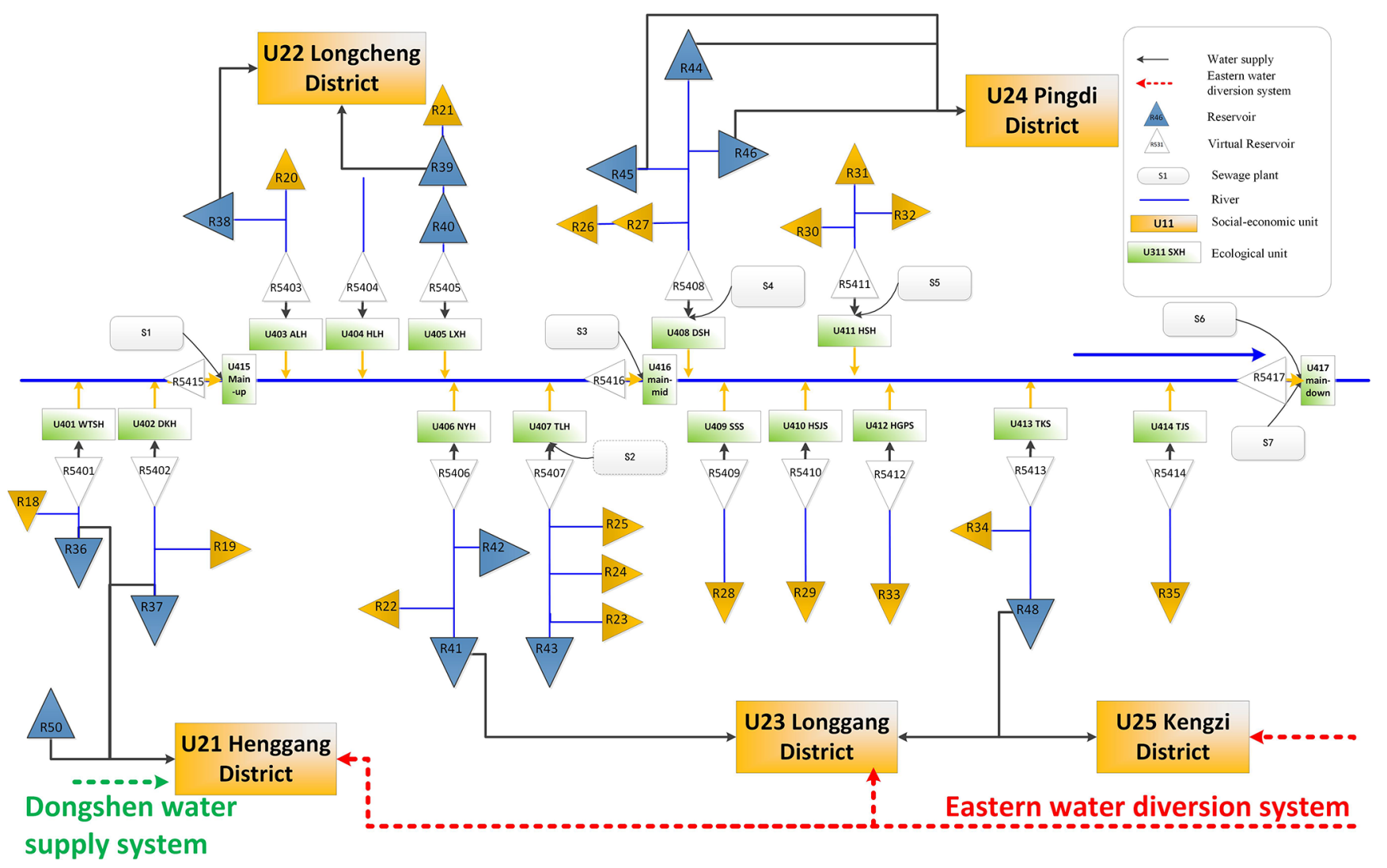

Figure 4. Water resource allocation network of the Longgang River Basin. 
Table 2. Relationship between control sections and ecological units.

\begin{tabular}{lll}
\hline $\begin{array}{l}\text { Control section } \\
\text { ID }\end{array}$ & $\begin{array}{l}\text { Control section } \\
\text { name }\end{array}$ & $\begin{array}{l}\text { Ecological unit } \\
\text { ID }\end{array}$ \\
\hline 1 & WTSH & $\mathrm{U} 401$ \\
2 & DKH & $\mathrm{U} 402$ \\
3 & ALH & $\mathrm{U} 403$ \\
4 & HLH & $\mathrm{U} 404$ \\
5 & LXH & $\mathrm{U} 405$ \\
6 & NYH & $\mathrm{U} 406$ \\
7 & TLH & $\mathrm{U} 407$ \\
8 & DSH & $\mathrm{U} 408$ \\
9 & SSS & $\mathrm{U} 409$ \\
10 & HSJS & $\mathrm{U} 410$ \\
11 & HSH & $\mathrm{U} 411$ \\
12 & HGPS & $\mathrm{U} 412$ \\
13 & TKS & $\mathrm{U} 413$ \\
14 & TJS & $\mathrm{U} 414$ \\
15 & MAIN-UP & $\mathrm{U} 415$ \\
16 & MAIN-MID & $\mathrm{U} 416$ \\
17 & MAIN-DOWN & $\mathrm{U} 417$ \\
\hline
\end{tabular}

0.91 for the validation period. Figure 5 shows the simulated runoff of the Longgang River. From the perspective of water cycle simulation, the model has nearly ideal accuracy.

\subsubsection{Validation of water supply for social and economic purposes}

The water supply for social and economic purposes in the region is the total amount of water supplied for industrial, domestic and agricultural purposes within the Longgang District, the social and economic unit in the Longgang River Basin. Figure 7 shows a comparison of the simulated water supply for social and economic purposes and statistical data for the water supply that were published in the Shenzhen Water Resource Bulletins (from 1995 to 2015). The error between the simulated water supply and the corresponding statistical data is within $10 \%$ for $80 \%$ of the years between 1995 and 2015 (Fig. 6). The 20-year average water supply that was obtained from the E-WAS was 195 million $\mathrm{m}^{3}$, which differs from the published average annual water supply $\left(198\right.$ million $\left.\mathrm{m}^{3}\right)$ by 1.5 million $\mathrm{m}^{3}$; i.e., the relative error is $1.5 \%$. This indicates that the accuracy of the model in the generalized water resource network in the Longgang River Basin and the simulated water supply are acceptable.

\section{Results and discussion}

\subsection{Water allocation schemes}

To analyze the ecological water replenishment scheme for the Longgang River Basin, different operational schemes must be considered to configure the E-WAS framework. Con-
Table 3. Scheme for E-WAS calculation.

\begin{tabular}{ll}
\hline Scheme & Description \\
\hline 1 & $\begin{array}{l}\text { Reference scheme without replen- } \\
\text { ishment of ecological flow }\end{array}$ \\
\hline 2 & $\begin{array}{l}\text { Replenish ecological flow with } \\
\text { reclaimed water }\end{array}$ \\
\hline 3 & $\begin{array}{l}\text { Replenish ecological flow with } \\
\text { reservoir release }\end{array}$ \\
\hline
\end{tabular}

sidering multiple combinations of reclaimed water and surface water (reservoirs), the following three schemes are set to identify the ability of water replenishment for river channels with different water resources (Table 3).

The allocation of water resources under the three schemes is optimized using the E-WAS framework, with suitable ecological flows as the main operation constraints and targets. In this study, the satisfactory degree of ecological water demand (SDE, Eqs. 10-11) is used as an index to judge flow conditions in the river.

$$
\begin{aligned}
& \operatorname{SDE}(x)_{\text {month }}=1-\frac{\max \left(0, \mathrm{de}_{i}(x)-\operatorname{rep}_{i}(x)\right)}{\operatorname{de}_{i}(x)} \\
& \operatorname{SDE}(x)_{\text {year }}=1-\frac{\sum_{i=1}^{12} \max \left(0, \operatorname{de}_{i}(x)-\operatorname{rep}_{i}(x)\right)}{\sum_{i=1}^{12} \operatorname{de}_{i}(x)}
\end{aligned}
$$

where $\operatorname{SDE}(x)_{\text {month }}$ is the monthly satisfactory degree of ecological water demand of river section $x ; \operatorname{SDE}(x)_{\text {year }}$ is the annual satisfactory degree of ecological water demand of river section $x$; $\operatorname{rep}_{i}(x)$ is the monthly/annual water replenishment of river section $x$; and $\mathrm{de}_{i}(x)$ is the monthly/annual ecological water demand of river section $x$. Table 4 shows the annual SDE (Eq. 9) associated with each scheme as well as the water replenishment capacity (WRC, $10000 \mathrm{~m}^{3}$ ) of multiple water sources in a typical dry year $(P=75 \%)$. The WRC is given by the E-WAS framework after long term water allocation calculation.

For the ecological water replenishment of a river basin, it is necessary to account for the extent to which the water requirements are satisfied, as well as various other factors such as engineering and economic factors. Thus, the following principles are proposed for the optimization of the ecological water allocation scheme:

- The reservoirs are prioritized to ensure that the water requirements for social and economic purposes in the Longgang River Basin are satisfied.

- Regarding water replenishment measures for tributaries, the priority is given to (1) reclaimed water from the upper reaches of the tributaries, followed by (2) water released from the reservoirs and (3) reclaimed water from 

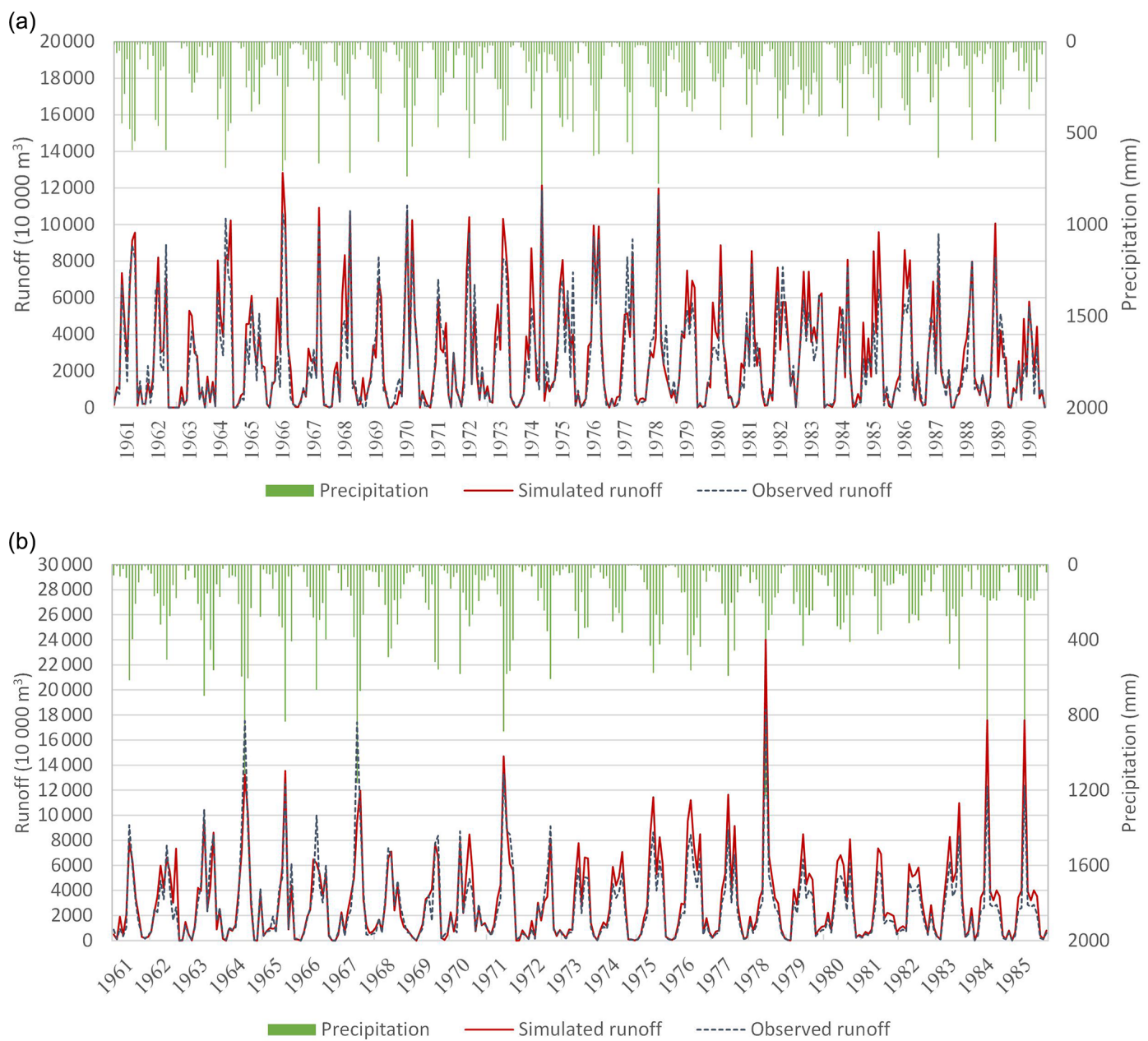

Figure 5. Runoff calibration (a) and validation (b) of the E-WAS framework.

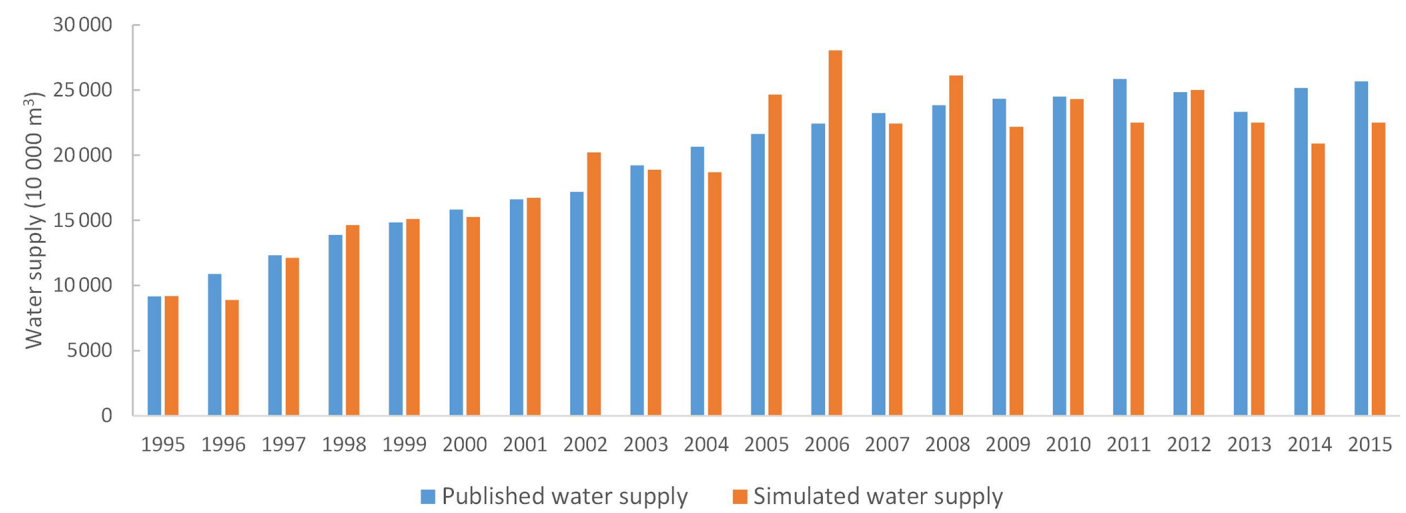

Figure 6. Comparison of water use between simulated and published data.

the lower reaches of the tributaries (water extraction is required).

- After the ecological flow in the tributaries has been increased, the main stream is replenished with water from the tributaries. It is first ensured that the ecological wa- ter requirements of each tributary are satisfied, which will indirectly ensure that the ecological water requirements of the main stream are also satisfied.

- For a river with no reclaimed water and reservoir water resources, measures that extract water from the main 

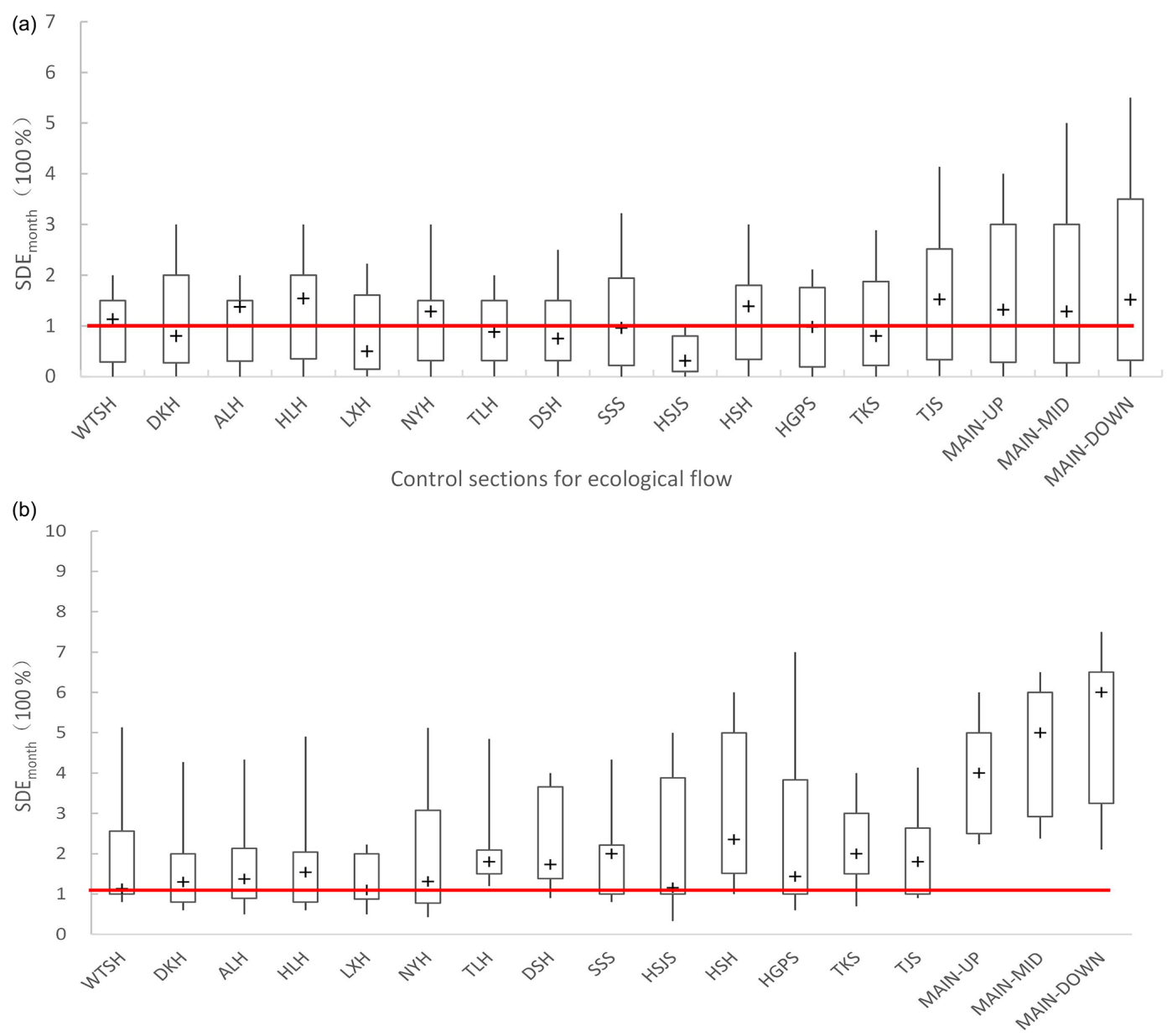

Control sections for ecological flow

Figure 7. Different $\mathrm{SDE}_{\text {month }}$ of each section before (a) and after (b) implementing the recommended water replenishment scheme.

stream or connect water systems to achieve ecological water replenishment will be considered.

Based on the above principles, as well as the water deficiencies and the replenishment capacity of each scheme that is shown in Table 3, an optimized ecological water replenishment scheme for the Longgang River Basin is formulated (Table 5). Reclaimed water generated from the sewage plants is used to replenish tributaries such as the WTSH, the DKH, the DSH, the HSH, the TKS and the TJS. Ten reservoirs (R18, R19, R20, R40, R42, R22, R43, R25, R23 and R33) are used to improve the ecological flows in tributaries such as the WTSH, the DKH, the ALH, the LXH, the NYH, the TLH and the HGPS. The flow in the main stream is mainly indirectly replenished through the cumulative effects achieved by replenishing tributaries; i.e., the main stream is replenished with water from the tributaries. The SDEs of the HLH, SSS and HSJS in Scheme 1 are relatively high (89\%), so there is no need for water replenishment in these two tributaries.

\subsection{Effects of the recommended water replenishment schemes}

To further analyze the effectiveness of the E-WAS framework, the SDE is analyzed from temporal and spatial perspectives. Boxplots were produced to analyze the monthly SDE (Eq. 8) in each unit in a typical dry year $(P=75 \%)$ before and after the ecological water replenishment scheme (Fig. 7). Without a replenishment scheme, there are fewer than six months in which the ecological flows at the 17 control sections are ensured and the SDEs of tributaries WTSH, TLH, LXH and HSJS are relatively low. With the recommended water replenishment scheme, the $\mathrm{SDE}_{\mathrm{year}}$ increases significantly, and there are more than six months in which the ecological flow at each section is ensured. In addition, the $\mathrm{SDE}_{\text {month }}$ of the aforementioned sections also increases considerably.

The recommended ecological water replenishment scheme mainly focuses on tributaries characterized by ecological water deficiencies. Through the operation of the reservoirs and the use of reclaimed water, the ecological flows in the tribu- 
Table 4. SDE and WRC under three E-WAS schemes in a typical dry year $(P=75 \%)$.

\begin{tabular}{|c|c|c|c|c|c|}
\hline \multirow[t]{2}{*}{ ID } & \multirow{2}{*}{$\begin{array}{l}\text { Control } \\
\text { sections }\end{array}$} & \multicolumn{2}{|c|}{ Scheme 1} & \multirow{2}{*}{$\begin{array}{r}\text { WRC in Scheme } 2 \\
\left(10000 \mathrm{~m}^{3}\right)\end{array}$} & \multirow{2}{*}{$\begin{array}{r}\text { WRC in Scheme } 3 \\
\left(10000 \mathrm{~m}^{3}\right)\end{array}$} \\
\hline & & $\begin{array}{r}\mathrm{SDE}_{\text {year }} \\
(\%)\end{array}$ & $\begin{array}{l}\text { Water deficiency } \\
\qquad\left(10000 \mathrm{~m}^{3}\right)\end{array}$ & & \\
\hline 1 & WTSH & 83 & 205 & 1080 & 348 \\
\hline 2 & DKH & 84 & 154 & 438 & 17 \\
\hline 3 & ALH & 84 & 126 & 0 & 89 \\
\hline 4 & HLH & 89 & 73 & 0 & 0 \\
\hline 5 & LXH & 62 & 650 & 1800 & 528 \\
\hline 6 & NYH & 83 & 319 & 0 & 225 \\
\hline 7 & TLH & 83 & 194 & 0 & 268 \\
\hline 8 & DSH & 83 & 518 & 2737 & 86 \\
\hline 9 & SSS & 89 & 8 & 0 & 46 \\
\hline 10 & HSJS & 89 & 10 & 0 & 127 \\
\hline 11 & HSH & 83 & 269 & 350 & 178 \\
\hline 12 & HGPS & 80 & 13 & 0 & 66 \\
\hline 13 & TKS & 77 & 181 & 2880 & 188 \\
\hline 14 & TJS & 84 & 72 & 1080 & 75 \\
\hline 15 & MAIN-UP & 83 & 359 & 7200 & 364 \\
\hline 16 & MAIN-MID & 82 & 1721 & 10800 & 1470 \\
\hline 17 & MAIN-DOWN & 82 & 2841 & 36360 & 2261 \\
\hline
\end{tabular}

Table 5. Recommended ecological water replenishment scheme for a typical dry year $(P=75 \%)$.

\begin{tabular}{lllrr}
\hline ID & $\begin{array}{l}\text { Control } \\
\text { section }\end{array}$ & $\begin{array}{l}\text { Water resource for replenishment } \\
\text { in recommended scheme }\end{array}$ & $\begin{array}{r}\text { Water replenishment } \\
\left(10000 \mathrm{~m}^{3} \mathrm{yr}^{-1}\right)\end{array}$ & $\begin{array}{r}\text { SDE } \\
\text { year }\end{array}$ \\
\hline 1 & WTSH & R18, S1 & 205 & $100 \%$ \\
2 & DKH & R19, S1 & 154 & $100 \%$ \\
3 & ALH & R20 & 89 & $96 \%$ \\
4 & HLH & - & - & $89 \%$ \\
5 & LXH & R40 & 528 & $93 \%$ \\
6 & NYH & R42,R22 & 225 & $100 \%$ \\
7 & TLH & R43, R25, R23 & 194 & $100 \%$ \\
8 & DSH & S4 & 518 & $100 \%$ \\
9 & SSS & - & - & $89 \%$ \\
10 & HSJS & - & - & $89 \%$ \\
11 & HSH & S5 & 269 & $100 \%$ \\
12 & HGPS & R33 & 18 & $100 \%$ \\
13 & TKS & S6 & 181 & $100 \%$ \\
14 & TJS & S7 & 72 & $100 \%$ \\
15 & MAIN-UP & From tributaries & 359 & $100 \%$ \\
16 & MAIN-MID & From tributaries & 1395 & $96 \%$ \\
17 & MAIN-DOWN & From tributaries & 2841 & $100 \%$ \\
\hline
\end{tabular}

taries are ensured, which in turn impacts the main stream of the Longgang River and significantly increases the SDE.

\subsection{Improvement of the allocation model}

The E-WAS framework is an improvement to the WAS model and includes both constraint-type and target-type features in the ecological operation model. The effectiveness of the EWAS framework in ensuring that the ecological water re- quirements of the river and allocating water for social and economic purposes is evaluated by comparing the statistical indices of the results obtained from the WAS model and the E-WAS framework. Two schemes are used (Table 6). For scheme 1, the WAS model is employed to simulate the allocation of water resources in the study area. The results that were obtained using the E-WAS framework (Sect. 4.1) are used as the results for scheme 2 . The value of the global ob- 
Table 6. Different objective function values in WAS and E-WAS.

\begin{tabular}{llr}
\hline Objective functions & \multicolumn{2}{c}{ Model } \\
\cline { 2 - 3 } & WAS & E-WAS \\
\hline GOB (global objective function) & $90 \%$ & $93 \%$ \\
\hline $\begin{array}{l}\text { SDSE (satisfactory degree of social and } \\
\text { economic water demand) }\end{array}$ & $93 \%$ & $92 \%$ \\
\hline $\begin{array}{l}\text { SDE } \begin{array}{l}\text { ical water demand) } \\
\text { icalisfactory degree of ecolog- }\end{array} \\
74 \%\end{array}$ & $95 \%$ \\
\hline
\end{tabular}

jective function is the mean of the equity objective function (Eq. 4) and the water deficiency objective function (Eq. 6) that were presented in Sect. 2.

In scheme 1, the WAS model, which does not consider the ecological water requirements of the river channels, is employed, and only water consumption for social and economic purposes is considered during the allocation process. By allocating various water resources, the SDSE reaches 93 percent, and the GOB also reaches $90 \%$; however, the $\mathrm{SDE}_{\text {year }}$ is relatively low (only $74 \%$ ). In scheme 2 , the E-WAS computational framework, which is oriented to ecological water replenishment, is used. This framework considers the water requirements for social and economic purposes and considers the ecological flows in the main stream and tributaries. Under scheme 2, the GOB reaches $93 \%$; in addition, the SDSE decreases slightly to $92 \%$, and the $\mathrm{SDE}_{\text {year }}$ reaches $95 \%$.

\section{Conclusions}

1. By generalizing the river sections with ecological water requirements, which are treated as ecological units, ecological control targets are included in the E-WAS framework. By establishing links between various water sources and economic and ecologic units, a multiobjective long-term simulation is realized to obtain an allocation scheme that satisfies ecological flows at the control sections of the river channels. Under the E-WAS framework, simulations of ecological replenishment in a river basin considers SDEs and various other factors (e.g., engineering and economic factors). The ecological water replenishment scheme is further optimized based on all the usable water sources and the principle that the main stream and tributaries are coordinated, and the upper and lower reaches are used to replenish one another. Compared with other ecological operation models and ecological water replenishment method, the framework proposed in this paper does not alter the internal computational structure of the model with the aid of virtual reservoirs and units. Thus, it is similar to a model plugin, which helps researcher to avoid the large workload that is required for model redevelopment and can expand the function of model relatively quickly.
2. A case study of the Longgang River Basin in Shenzhen is performed to investigate the ecological operation with E-WAS. Fourteen ecological units with water requirements and one social-economic unit are set. The suitable ecological water requirements of the 17 ecological units are determined. A total of 45 water supply nodes, including reservoirs and sewage plants are considered in a coordinated manner. Based on the E-WAS, the ecological water requirements at each section are calculated, and the SDE under current conditions can be estimated. By comparing different water replenishment schemes, a water replenishment scheme that uses water from seven reservoirs and reclaimed water from six water sewage plants is selected to replenish the ecological flow at the 17 control sections. This scheme significantly increases the SDE (from $62 \%$ to $89 \%$ under the reference scheme to $89 \%$ to $100 \%$ ), and thus efficiently supports the formulation of a control scheme for the water environment of Shenzhen.

3. Computational frameworks such as E-WAS can be flexibly used for various regions. Particularly, under these frameworks, significantly different results with respect to the adjustment of priority levels for the water supply for various sectors will be obtained (in this study, the priority levels for water supply for ecological purposes and for social-economic purposes are the same). This is determined by the levels of importance that are attached to water consumption for social and economic sectors and the ensuring of ecological flows in the river channels in the region. When ecological improvement is set to a high priority level in the E-WAS, the SDE will increase further. Under this condition, due to the constraint of the global objective function, there will not be relatively large deficiencies in water use for social and economic purposes.

4. At present, the E-WAS framework does not include a prediction function, and it is distinguished from a real time reservoir operation model. Thus, the framework is more useful in the planning stage. It can be used as a tool for controlling the use of water resources for water replenishment planning and to provide scheme for regional water control planning to promote rational management of water resources, alleviate contradictions to water demand over supply and improve the flow into the river on the regional and even national levels.

Data availability. All data can be accessed via the references.

Author contributions. The research was designed, the necessary data collected and conclusions drawn by all five authors in collaboration. ZY wrote the main part of the article, ZZ made comments and suggested improvements. YJ and HW served as the primary 
writer and expert on water replenishment. XS served as expert on model.

Competing interests. The authors declare that they have no conflict of interest.

Special issue statement. This article is part of the special issue "Hydrological processes and water security in a changing world". It is a result of the 8th Global FRIEND-Water Conference: Hydrological Processes and Water Security in a Changing World, Beijing, China, 6-9 November 2018.

Acknowledgements. This study was supported by the National Key Research and Development Program of China (no. 2016YFC0402405), the National Natural Science Foundation of China (nos. 51779270, 51309248), Shenzhen Project (SZCG2016121595B), the Foundation of CWEPC (CSCEC-PSH2017-03), and the Foundation of SKL-WAC (SKL2018TS04).

Financial support. This research has been supported by the National Key Research and Development Program of China (grant no. 2016YFC0402405), the National Natural Science Foundation of China (grant nos. 51779270 and 51309248), Shenzhen Project (grant no. SZCG2016121595B), the Foundation of CWEPC (grant no. CSCEC-PSH-2017-03), and the the Foundation of SKL-WAC (grant no. SKL2018TS04).

\section{References}

Armbruster, J. T.: An infiltration index useful in estimating lowflow characteristics of drainage basins, J. Res. USDS, 4, 533538, https://doi.org/10.1255/jnirs.866, 1976.

Binns, N. A. and Eiserman, F. M.: Quantification of fluvial trout habitat in Wyoming, T. Am. Fish. Soc., 108, 215-228, https://doi.org/10.1577/15488659(1979)108<215:QOFTHI>2.0.CO;2, 1979.

Cui, B. S., Yang, Q. C., Yang, Z. F., and Zhang, K. J.: Evaluating the ecological performance of wetland restoration in the Yellow River Delta, China Ecol. Eng., 35, 1090-1093, https://doi.org/10.1016/j.ecoleng.2009.03.022, 2009.

Day, J., Hunte, R., Keim, R. F., DeLaune, R., Shaffer, G., Evers, E., Reed, D., Brantley, C., Kemp, P., Day, J., and Hunter, M.: Ecological response of forested wetlands withand without Large-Scale Mississippi River input: implications for management, Ecol. Eng., 46, 57-67, https://doi.org/10.1016/j.ecoleng.2012.04.037, 2012.

Dong, Z. R.: Multi-objective ecological operation of reservoirs, Technology of Water Conservancy and Hydropower, 38, 28-32, 2007 (in Chinese).

Galat, D. L., Fredrickson, L. H., Humburg, D. D., Bataille, K. J., Bodie, J. R, Dohrenwend, J., Gelwicks, G. T., Havel, J. E., Helmers, D. L., Hooker, J. B., Jones, J. R., Knowlton, M. F., Kubisiak, J., Mazourek, J., McColpin, A. C., Renken, R. B., and Semlitsch, R. D.: Flooding to Restore Connectivity of Regulated, Large-River Wetlands. BioScience, 48, 721-733, https://doi.org/10.2307/1313335, 1998.

Gippel, C. J. and Stewardson, M. J.: Use of wetted perimeter in defining minimum environmental flows, Regul. River., 14, 53-67, https://doi.org/10.1002/(SICI)10991646(199801/02)14:1<53::AID-RRR476>3.0.CO;2-Z, 1998.

Gippel, C. J., Jacobs, T., and McLeod T.: Determining environmental flow needs and scenarios for the River Murray System, Australia, Australian Journal of Water Resources, 5, 61-74, https://doi.org/10.1080/13241583.2002.11465193, 2002.

Gore, J. A. and Nestler, J. M.: Instream flow studies in perspective, Regul. River., 2, 93-101, https://doi.org/10.1002/rrr.3450020204, 1988.

Gregoiy, D. E.: Development of instream flow recommendations in Colorado using R2cross, Dept. Colorado Water Conservation Board, Denver, Colorado, USA, 1996.

Higgins, J. M. and Brock, W. G.: Overview of reservoir release improvement at 20TVA dams, J. Energ. Eng., 125, 1-17, https://doi.org/10.1061/(ASCE)0733-9402(1999)125:1(1), 1999.

Huang, T. M. and Pang, Z. H.: Changes in groundwater induced by water diversion in the Lower Tarim River, Xinjiang Uygur, NW China: evidence from environmental isotopes and water chemistry, J. Hydrol., 387, 188-191, https://doi.org/10.1016/j.jhydrol.2010.04.007, 2010.

Hughes, D. A. and Hannart, P.: A desktop model used to provide an initial estimate of the ecological instream flow requirements of rivers in South Africa, J. Hydrol., 270, 167-181, https://doi.org/10.1016/S0022-1694(02)00290-1, 2003.

Junk, W. J.: Amazonian floodplains: Their ecology, present and potential use, Revue d'Hydrobiologie Tropicale, 15, 285-301, 1982.

King, J. and Louw, D.: In stream flow assessments for regulated rivers in South Africa using the Building Block Methodology, Aquat. Ecosyst. Health, 1, 109-124, https://doi.org/10.1080/14634989808656909, 1998.

Mao, X. L., Tian, K., Li, T. H., and Xu, Y.: Characteristics of Urban Ecological Water Requirement in Baoan, Shenzhen, Acta Scientiarum Naturalium Universitatis Pekinensis, 45, 721-727, https://doi.org/10.13209/j.0479-8023.2009.107, 2009 (in Chinese).

Petts, G. E.: Water allocation to protect river ecosystems, Regul. River., 12, 353-365, https://doi.org/10.1002/(sici)10991646(199607)12:4/5<353::aid-rrr425>3.0.co;2-6, 1996.

Sang, X. F, Zhou, Z. H., Wang, H., Qin, D. Y., Zhai, Z. L., and Chen, Q.: Development of soil and water assessment tool model on human water use and application in the area of high human activities, Tianjin, China, J. Irrig. Drain. E., 136, 23-30, https://doi.org/10.1061/(ASCE)IR.1943-4774.0000115, 2010.

Singh, K. P. and Stall, J. B.: Hydrology of 7-day 10-yr low flows, J. Hydraul. Eng., 100, 1753-1771, 1974.

Symphorian, G. R., Madamombe, E., and Van der Zaag, P.: Dam operation for environmental water releases; the case of Osborne dam, Save catchment, Zimbabwe, Phys. Chem. Earth, 28, 985993, https://doi.org/10.1016/j.pce.2003.08.012, 2003.

Tennant, D. L.: Instream flow regimens for fish, wildlife, recreation and related environmental resources, Fisheries, 1, 6-10, https://doi.org/10.1577/15488446(1976)001<0006:IFRFFW>2.0.CO;2, 1976. 
Wang, J. H., Sang, X. F., Zhai, Z. L., Liu, Y., and Zhou, Z. H.: An Integrated Model for Simulating Regional Water Resources Based on Total Evapotranspiration Control Approach, Adv. Meteorol., 2014, 345671, https://doi.org/10.1155/2014/345671, 2014.

Yan, Z. Q., Zhou, Z. H., Sang, X. F., and Wang, H.: Water replenishment for ecological flow with an improved water resources allocation model, Sci. Total Environ., 643, 1152-1165, https://doi.org/10.1016/j.scitotenv.2018.06.085, 2018.

Yang, W., Yang, Z. F., and Sun, T.: A review of requirement quantity and allocation of ecological water for wetland, Wetland Sci., 6 , 532-535, 2008

Yang, X., Chen, G., Sang, X. F., Gu, S. X., and Zhou, Z. H.: Water Resources Allocation at Plateau Lakes Based on Interconnected River System Network, China Rural Water and Hydropower, 9, 205-211, 2016.
Zhai, Z. L., Sang, X. F., Chen, J., and Yang, M.: The Total Control of Water Supply and Water Consumption in Tianjin City Based on WAS Model. 2017 3rd International Conference on Green Materials and Environmental Engineering, 22-23 October 2017, Beijing, China, 2017.

Zhou, L. F., Xu, S. G., Li, Q. S., and Liu, D. Q.: Safety threshold of eco-environmental water requirement in wetland, J. Hydraulic Eng., 38, 845-851, https://doi.org/10.3321/j.issn:05599350.2007.07.013, 2007 (in Chinese). 